\title{
Information Complements, Substitutes, and Strategic Product Design
}

\author{
By: Geoffrey G. Parker and Marshall W. Van Alstyne \\ Working Paper Number 299 \\ March 2000
}




\author{
Information Complements, Substitutes, and Strategic Product Design \\ Geoffrey G. Parker \\ Tulane University \\ Freeman School of Business \\ New Orleans, LA 70118 \\ 504.865 .5472 \\ geoffrey.parker@tulane.edu \\ Marshall W. Van Alstyne \\ University of Michigan \\ School of Information \\ Ann Arbor, MI 48109 \\ 734.647 .8028 \\ mvanalst@umich.edu
}

March 24, 2000

\begin{abstract}
Competitive maneuvering in the information economy has raised a pressing question: how can firms raise profits by giving away products for free? This paper provides a possible answer and articulates a strategy space for information product design. Free strategic complements can raise a firm's own profits while free strategic substitutes can lower profits for competitors.

We introduce a formal model of cross-market externalities based in textbook economics - a mix of Katz \& Shapiro network effects, price discrimination, and product differention - that leads to novel strategies such as an eagerness to enter into Bertrand price competition. This combination helps to explain many recent firm strategies such as those of Microsoft, Netscape (AOL), Sun, Adobe, and ID. We also introduce the concept of a "content-creator" who adds value for end-consumers but may not be paid directly. This research implies that both firms and policy makers need to consider complex market interactions to grasp information product design and profit maximization.

The model presented here argues for three simple and intuitive results. First, a firm can rationally invest in a product it intends to give away into perpetuity even in the absence of competition. The reason is that increased demand in a complementary goods market more than covers the cost of investment in the free goods market.

Second, we identify distinct markets for content-providers and end-consumers and show that either can be a candidate for the free good. The decision on which market to charge rests on the relative elasticities as governed by their network externality effects. If the externality effect is sufficiently large, the market with the higher elasticity is the market to subsidize with the free good. It is also possible to charge both markets but to keep one price artificially low. The modeling contribution is distinct from tying in the sense that consumers need never purchase both goods. Unlike razors and blades, the products are stand-alone goods. It also differs from multi-market price discrimination in the sense that the firm may extract no consumer surplus from one of the two market segments, implying that this market would have previously gone un-served.

Third, a firm can use strategic product design to penetrate a market that becomes competitive post-entry. The threat of entry is credible even in cases where it never recovers its sunk costs directly. The model therefore helps to explain several interesting market behaviors such as free goods, upgrade paths, split versioning, and strategic information substitutes.

This research has been generously supported by the Freeman School of Business and by an NSF Career Award \#IIS 9876233.
\end{abstract}




\section{Introduction}

In the information economy, competitive maneuvers have raised the question of when firms can increase profits by giving away free product. Microsoft and Netscape (now part of AOL) competed by finding ever more channels through which to freely distribute their browser software. Adobe widely distributes its portable document reader. Real Audio permits anyone to download its sound player. Sun Microsystems has acquired Star, the most successful developer of an office suite for Linux, in order to give its products away.

This paper provides one answer to the question. Free strategic complements can raise profits for goods owned by the same firm. The model predicts that firms may integrate or incur significant development costs in order to distribute portions of a pair of complements. In contrast, free strategic substitutes can lower profits for competitors inducing market exit when average cost curves are declining. Incumbents then benefit from reduced competition.

One novel modeling contribution is to introduce the concept of a content provider, a distinct market segment that adds value for the end-consumer but that may not be paid directly. This explains, for example, the production of Real Audio content for Real Audio players and Acrobat articles for Acrobat readers that have nothing to do with the firms Real Audio or Adobe respectively. We also show that distinct market strategies emerge yielding alternative free goods markets and fare goods markets. A comparative statics analysis shows when firms make profits by charging positive prices in either the end-consumer or the content provider markets, or both.

The key insight is that designing a separable product and underpricing one component is a device for implementing price discrimination in markets with positive network externalities. The apparent contradiction of introducing and sustaining a product subsidy in one market resolves itself once it becomes clear how profits increase more than the subsidy cost in the other market. This product coupling strategy can also be used to extend the sphere of product competition to oligopoly markets. The cross-market subsidy made possible by 
the positive externality ensures that one firm can not only sustain an indefinite subsidy, but can even increase its profits in competition with another firm. Interestingly, this undercuts the conventional wisdom that firms should seek to avoid Bertrand price competition as this forces price to marginal cost. As in the case of the Internet browser wars, our framework illustrates how prices below marginal cost can be profit maximizing when they serve to stimulate demand across markets. Correspondingly, this may help to explain the ubiquity of free information offered on the Internet.

The mechanisms rely on fairly standard intuitions but, in fact, alter the standard models. This leads to subtle differences with the network externality and price discrimination literatures at the same time we draw heavily from both. In particular, we extend the idea of an intra-market network externality, or demand economy of scale, to an inter-market externality. In the classic exchange story, consumers of telephones benefit from increased consumption of telephones as this extends the reach of existing consumers to new consumers. In contrast, consider the chicken-and-egg problem of creating music content for a new format. Producers want consumers and consumers want producers before either readily switches to the new format.

An incumbent firm producing music content probably does not welcome entry by another firm producing similar content as there is no profitable direct exchange between them. Everyone in the end consumer market, however, welcomes entry because it increases the prospect of a viable format should the incumbent fail. It also increases variety while possibly lowering prices. This increases both the value to individuals and the number of individuals willing to switch formats. Thus, in the present example, the externality runs from content creators to end consumers.

Conversely, consider the end consumer's original choice of VHS versus Beta. Initially, at least, consumers are likely to care less about adding any single consumer to a new format than they care about the number and diversity of firms who provide content for that format. Producers, however, care immensely about the size of the consumer market. The existence of a larger consumer base makes 
production under any given format more attractive. Again, in the present example, the externality runs across markets from consumers to providers of content and back. Importantly, both content creators and consumers do value growth in their own markets but this may be mediated by the indirect effect of the crossmarket externality. At issue is whether own-market entry expands participation on the other side of each transaction. Content creators may not object to other content providing firms if effective consumer demand rises instead of falls.

Consider finally, a third participant - the focus of our attention here - who produces tools to support both content creators and end consumers. Examples include Sun, Apple, and Microsoft who support software developers as well as private and business buyers; it includes Sony and Phillips who support the entertainment industry as well as households; and it includes firms like Adobe who produce portable document distillers as well as portable document readers. For these firms, the chicken-and-egg profit maximization problem is how to grow both markets. A straightforward solution that is widely observed in the internet economy is to subsidize one market in order to profit more from the other.

To put this in context, this idea differs somewhat from traditional multimarket, or third degree, price discrimination in that firms make product offers to markets where they never intend to capture any consumer surplus. In fact, they may subsidize one market indefinitely to promote demand in the other. Thus we extend the analysis in which consumer values are fixed and the only contracts available in the marketplace are those designed to extract surplus from those who accept them.

The insights also differ somewhat from the traditional models of tying, or second degree price discrimination. Although the strategic choice of product design requires both goods to be coupled, unlike the classic case of razors and blades, at least one of market segment need never consume the complementary good. Consumers of a portable document reader may, at their discretion, forgo the cost of the distiller illustrating how the goods are more loosely coupled than in the classic cases of tying.

We note that the popularity of this product design strategy among informa- 
tion goods may in part be due to the unique properties of information. Because the first copy costs are high but the second copy costs are negligible, a firm can afford to subsidize an arbitrarily large market while only incurring a fixed up-front investment cost. Each additional consumer of the free good costs the clever product designer nearly nothing in incremental costs. With increased consumption of information, we may expect to see increased use of the proposed product design strategy in the future.

\section{Related Literature}

This analysis proceeds from a diverse literature. The concept of strategic complements and substitutes was introduced by Bulow, Geanakoplos, and Klemperer (1985). The definition of strategic complements (substitutes) differs from the standard definition in the emphasis on marginal rather than total profit increase (decrease) with the introduction of new goods. An example where firms prefer to enter zero profit markets is presented in DeGraba (1996). The mechanism, however, is quite different. That analysis begins with a model of tying based on Whinston's (1990) contribution and relies on declining average cost curves to favor firms with increased sales. Our model makes less use of tying - the consumption decision for both goods is voluntary and one market may never purchase both goods - and instead relies on the content provider market to increase sales, yielding different selling and product design strategies. Shapiro and Varian (1999) discuss the possibility of negative pricing to profit in complementary markets. We formally model when this is optimal and how a third party, the content creator, contributes value to consumers. These strategies are similar to an extreme form of product versioning (Varian 1997), but include the benefit of strategic complements. The complement is modeled after the network externality framework of Katz and Shapiro (1985). This work also adds to the work on bundling (Adams and Yellen 1976; Bakos and Brynjolfsson 1997; Nalebuff 1999) and mixed bundling (Chuang and Sirbu 1997). Where prior research characterizes the profit motives for bundling information goods 
in monopolistic and competitive (Fay and MacKie-Mason 1999) settings, this work characterizes the profit motives for unbundling information goods. The innovation is that we articulate the opposite end of the spectrum of tastes. The bundling literature focuses on little or negative correlation in consumer tastes; in contrast, this contribution focuses on strong positive correlation, through the information product design decision.

The paper proceeds as follows. First, we develop a model of complements. We then find the conditions for a subsidy market to exist and prove uniqueness in a two market setting. We develop a model of oligopoly competition in the presence of cross-market externalities and show how firms can take advantage of both positive and negative externalities. Finally, we explore when firms will find it advantageous to disaggregate information goods for sale to distinct markets.

\section{A Model of Complements}

In this section we consider the question of why a firm should spend resources to create a product it intends to distribute for free. Drawing on complementary goods markets where there are demand economies of scale, the model shows that participating in a free goods market can be profit maximizing.

\subsection{Markets}

We consider two markets for a given information product. The first is the general consumer market (subscript c). The second market is the joint-producer or content-creator market (subscript j). Building on Katz and Shapiro (1985), we model each consumer's willingness to pay as a function of the their own valuation and the number of consumers in the other market who buy.

The parameter $\mathrm{Q}$ is a bound on the quantity purchased and $\mathrm{V}$ is a bound on consumers' valuations for the product in the absence of externalities. The externality term $e_{j c}$ determines how much of an impact purchases in the joint- 
producer market have on the consumer market. Conversely, $e_{c j}$ determines how much of an impact purchases in the consumer market have on the joint-producer market. In order to work with linear demand curves, we assume that potential consumers in each market have a uniform distribution of valuations, but share their valuation of the externality from the alternate market. This yields the pair of simultaneous equations:

$$
\begin{aligned}
& q_{c}=Q_{c}+e_{j c} q_{j}-\frac{Q_{c}}{V_{c}} p_{c} \\
& q_{j}=Q_{j}+e_{c j} q_{c}-\frac{Q_{j}}{V_{j}} p_{j}
\end{aligned}
$$

Eliminating $q_{i}$ from the right-hand-side in each equation leads to independent formulae:

$$
\begin{aligned}
& q_{c}=\frac{Q_{c}+e_{j c} Q_{j}}{1-e_{c j} e_{j c}}-\frac{Q_{c} p_{c}}{\left(1-e_{c j} e_{j c}\right) V_{c}}-\frac{e_{j c} Q_{j} p_{j}}{\left(1-e_{c j} e_{j c}\right) V_{j}} \\
& q_{j}=\frac{Q_{j}+e_{c j} Q_{c}}{1-e_{c j} e_{j c}}-\frac{Q_{j} p_{j}}{\left(1-e_{c j} e_{j c}\right) V_{j}}-\frac{e_{c j} Q_{c} p_{c}}{\left(1-e_{c j} e_{j c}\right) V_{c}}
\end{aligned}
$$

To render the interpretation meaningful, we impose the restriction that $1-$ $e_{c j} e_{j c}>0$ in order that the network externality terms contribute only a finite and positive amount to consumer surplus.

\subsection{Monopoly Choice}

Allowing for near zero marginal costs to distribute an information good, we can model the firms profit for the bundled good as $\pi=p q$. When the firm disaggregates the product for sale to two different markets, this becomes $\pi=$ $p_{c} q_{c}+p_{j} q_{j}$. 
Taking first-order conditions leads to the following monopoly choices for $p_{c}$ and $p_{j}$ :

$$
\begin{aligned}
& p_{c}^{*}=\frac{\left(e_{c j} e_{j c}-2\right) Q_{c} Q_{j} V_{c}^{2} V_{j}+e_{c j} Q_{c} Q_{j} V_{c} V_{j}^{2}-e_{j c} Q_{j}^{2} V_{c}^{2} V_{j}+e_{c j}^{2} Q_{c}^{2} V_{c} V_{j}^{2}}{2\left(e_{c j} e_{j c}-2\right) Q_{c} Q_{j} V_{c} V_{j}+e_{c j}^{2} Q_{c}^{2} V_{j}^{2}+e_{j c}^{2} Q_{j}^{2} V_{c}^{2}} \\
& p_{j}^{*}=\frac{\left(e_{c j} e_{j c}-2\right) Q_{c} Q_{j} V_{c} V_{j}^{2}+e_{j c} Q_{c} Q_{j} V_{c}^{2} V_{j}-e_{c j} Q_{c}^{2} V_{c} V_{j}^{2}+e_{j c}^{2} Q_{j}^{2} V_{c}^{2} V_{j}}{2\left(e_{c j} e_{j c}-2\right) Q_{c} Q_{j} V_{c} V_{j}+e_{c j}^{2} Q_{c}^{2} V_{j}^{2}+e_{j c}^{2} Q_{j}^{2} V_{c}^{2}}
\end{aligned}
$$

We can use these prices to determine $\pi^{*}$ as follows:

$$
\pi^{*}=\frac{Q_{c} V_{c}+Q_{j} V_{j}+e_{c j} Q_{c} V_{j}+e_{j c} Q_{j} V_{c}}{4-\left(\frac{e_{c j}^{2} Q_{c} V_{j}}{Q_{j} V_{c}}+2 e_{c j} e_{j c}+\frac{e_{j c}^{2} Q_{j} V_{c}}{Q_{c} V_{j}}\right)}
$$

In jointly maximizing prices over both markets, the normal assumptions of a positive first derivative and negative second derivative that guarantee concavity become the Hessian conditions. In the present model, the Hessian of

$$
\left(\begin{array}{cc}
\frac{\delta^{2} \pi}{\delta c^{2}} & \frac{\delta^{2} \pi}{\delta c \delta j} \\
\frac{\delta^{2} \pi}{\delta j \delta c} & \frac{\delta^{2} \pi}{\delta j^{2}}
\end{array}\right)
$$

yields $4-\left(\frac{e_{c j}^{2} Q_{c} V_{j}}{Q_{j} V_{c}}+2 e_{c j} e_{j c}+\frac{e_{j c}^{2} Q_{j} V_{c}}{Q_{c} V_{j}}\right)>0$.

We now introduce a simplification. We can map the maximum values, quantities and the externality terms into surplus space as follows:

$$
\begin{aligned}
S_{c} & =Q_{c} V_{c} \\
S_{j} & =Q_{j} V_{j} \\
S_{c j} & =e_{c j} Q_{c} V_{j} \\
S_{j c} & =e_{j c} Q_{j} V_{c}
\end{aligned}
$$

We can then express the optimal prices in surplus space:

$$
\begin{aligned}
p_{c}^{*} & =\frac{V_{c}\left(2 S_{c} S_{j}-S_{c j} S_{j c}+S_{j c} S_{j}-S_{c j}^{2}-S_{c j} S_{j}\right)}{4 S_{c} S_{j}-\left(S_{c j}+S_{j c}\right)^{2}} \\
p_{j}^{*} & =\frac{V_{j}\left(2 S_{c} S_{j}-S_{c j} S_{j c}+S_{c j} S_{c}-S_{j c}^{2}-S_{j c} S_{c}\right)}{4 S_{c} S_{j}-\left(S_{c j}+S_{j c}\right)^{2}}
\end{aligned}
$$


A simpler form for optimal profit can also be expressed in surplus space:

$$
\pi^{*}=\frac{S_{c} S_{j}\left(S_{c}+S_{c j}+S_{j c}+S_{j}\right)}{4 S_{c} S_{j}-\left(S_{c j}+S_{j c}\right)^{2}}
$$

The surplus space simplification provides a somewhat more congenial expression for the Hessian restriction and the finite market restriction:

$$
\begin{aligned}
4 S_{c} S_{j}-\left(S_{c j}+S_{j c}\right)^{2} & >0 \\
1-\frac{S_{c j} S_{j c}}{S_{c} S_{j}} & >0
\end{aligned}
$$

We now introduce a lemma to show that, in general, we need only satisfy the Hessian condition.

Lemma 1 The Hessian condition subsumes the finite market assumption. That is $4 S_{c} S_{j}-\left(S_{c j}+S_{j c}\right)^{2}>0$ yields a tighter bound than $1-\frac{S_{c j} S_{j c}}{S_{c} S_{j}}>0$.

Proof. Rewriting the finite market assumption, we have $S_{c} S_{j}>S_{c j} S_{j c}$ so clearly $4 S_{c} S_{j}-4 S_{c j} S_{j c}>0$. Thus we must show

$$
\begin{aligned}
4 S_{c} S_{j}-\left(S_{c j}+S_{j c}\right)^{2} & \leq 4 S_{c} S_{j}-4 S_{c j} S_{j c} \\
-\left(S_{c j}+S_{j c}\right)^{2} & \leq-4 S_{c j} S_{j c} \\
-S_{c j}^{2}-2 S_{c j} S_{j c}-S_{j c}^{2} & \leq-4 S_{c j} S_{j c} \\
-\left(S_{c j}^{2}-2 S_{c j} S_{j c}+S_{j c}^{2}\right) & \leq 0 \\
-\left(S_{c j}-S_{j c}\right)^{2} & \leq 0
\end{aligned}
$$

which is true for all values of $S_{c j}$ and $S_{j c}$. Indeed, the inequality is strict for all values $S_{c j} \neq S_{j c}$.

\subsection{The Choice of a Free Goods Market}

Choosing an optimal price pair is a standard maximization problem in price space. Using equations 3 and 4 above, we can plot prices $p_{c}$ and $p_{j}$ such that 


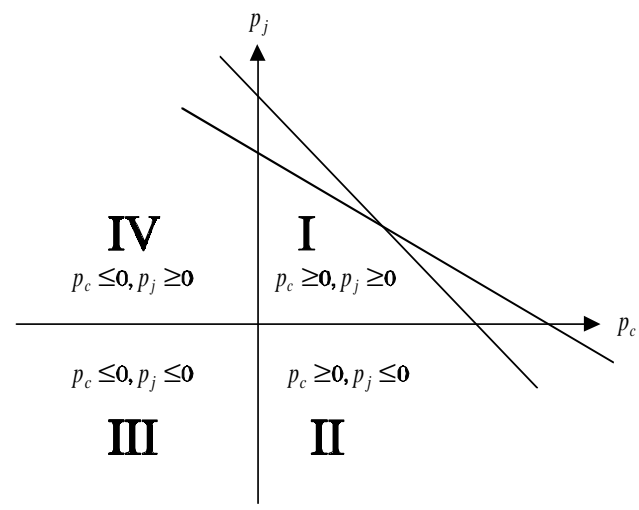

Figure 1: Four possible regions: (1) charge both consumers and joint-producers, (2) charge consumers, subsidize joint-producers, (3) subsidize both consumers and joint-producers, (4) subsidize consumers, charge joint-producers

quantities $q_{c}$ and $q_{j}$ are non-negative and then maximize $\pi$ over this convex region. The following plot illustrates the four regions where I - both markets are charged positive prices, II - joint producers are subsidized while consumers are charged positive prices, III - consumers are subsidized while joint-producers are charged positive prices. Region IV represents a subsidy to both markets and is never profit maximizing.

In general, the region of positive quantities is the area under both price curves. The relative market sizes, valuations, and network externalities, however, can give rise to different convex regions and optimal price choices.

In the next figure, we plot iso-profit curves in the case where the consumer market is charged.

In the figure above, profit is increasing as the iso-profit curves move downward and to the right. In principle, the markets are symmetric, implying that the choice of free and fare goods markets is not obvious. Although Figure 2 shows isoprofit curves increasing with subsidies to market $j$, rotating the plot 


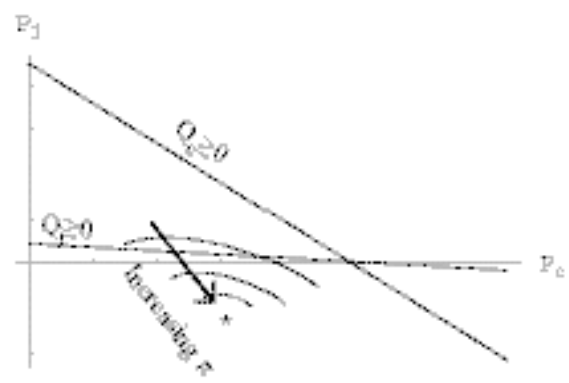

Figure 2: End consumers are charged while joint-producers are subsidized. * =optimal price choice

around the line yields a mirror image in which profit increases with subsidies to market $c$. In practice, Adobe charges for distiller in the content provider market while ID (publisher of the DOOM and Quake computer games) charges for the game player in the end consumer market.

The decision of which market to subsidize (if any) and which to charge rests on Proposition 1 below. First, we introduce a necessary lemma.

Lemma 2 If consumer prices are less than or equal to zero, it must be true that the consumer market creates more network surplus in the content-creator market than the content-creator market creates in the consumer market. That is, $p_{c}^{*} \leq 0$ implies $S_{c j}>S_{j c}$.

Proof. Using the finite market assumption, we derive a contradiction from the fact that price constrains the surplus terms in the stated proportions. Substituting surplus terms into the finite market assumption implies that $1-\frac{S_{c j} S_{j c}}{S_{c} S_{j}}>0$ or rather that $S_{c} S_{j}>S_{c j} S_{j c}$.

By the first order conditions, $p_{c}^{*}$ is given by:

$$
\frac{V_{c}\left(2 S_{c} S_{j}-S_{c j} S_{j c}-S_{j}\left(S_{c j}-S_{j c}\right)-S_{c j}^{2}\right)}{4 S_{c} S_{j}-\left(S_{c j}+S_{j c}\right)^{2}}
$$

and given that $p_{c}^{*} \leq 0$ the numerator must be $<0$ so we have

$$
2 S_{c} S_{j}-S_{c j} S_{j c}<S_{j}\left(S_{c j}-S_{j c}\right)+S_{c j}^{2}
$$


Because $S_{c j} S_{j c}<S_{c} S_{j}$, we have the further implication that

$$
\begin{aligned}
2 S_{c j} S_{j c}-S_{c j} S_{j c} & <2 S_{c} S_{j}-S_{c j} S_{j c}<S_{j}\left(S_{c j}-S_{j c}\right)+S_{c j}^{2} \\
S_{c j} S_{j c} & <S_{j}\left(S_{c j}-S_{j c}\right)+S_{c j}^{2} \\
S_{c j} S_{j c}-S_{c j}^{2} & <S_{j}\left(S_{c j}-S_{j c}\right) \\
S_{c j}\left(S_{j c}-S_{c j}\right) & <S_{j}\left(S_{c j}-S_{j c}\right)
\end{aligned}
$$

Both surplus terms $S_{c j}$ and $S_{j}$ are positive. Thus allowing $S_{c j}<S_{j c}$ leads to the contradiction that a positive number is less than a negative number from which it follows that $S_{c j}>S_{j c}$. Intuitively, the free goods market must create more network surplus in the fare goods market than vice versa in order to justify the subsidy.

Proposition 1 A free goods market exists for one of two markets linked by positive network externality terms when one of the following mutually exclusive conditions holds.

Consumer Market is Subsidized:

$$
\frac{2 S_{c} S_{j}}{S_{c j} S_{j c}+S_{j}\left(S_{c j}-S_{j c}\right)+S_{c j}^{2}}<1
$$

Content-Creator Market is Subsidized:

$$
\frac{2 S_{c} S_{j}}{S_{c j} S_{j c}+S_{c}\left(S_{j c}-S_{c j}\right)+S_{j c}^{2}}<1
$$

Proof. The ratios follow directly from the optimal prices and the Hessian condition. We now establish that only one market can be subsidized at a time. To do this, we assume that one market is subsidized and then derive a contradiction to the possibility using the Hessian Condition. 
Assume $p_{c}^{*}<0$. Then by the test condition we know that:

$$
\begin{aligned}
2 S_{c} S_{j} & <S_{c j} S_{j c}+S_{j}\left(S_{c j}-S_{j c}\right)+S_{c j}^{2} \\
2 S_{c} S_{j}-S_{c j} S_{j c} & <S_{j}\left(S_{c j}-S_{j c}\right)+S_{c j}^{2}
\end{aligned}
$$

The Hessian Condition implies that:

$$
\begin{aligned}
0 & <4 S_{c} S_{j}-\left(S_{c j}+S_{j c}\right)^{2} \\
S_{c j}^{2}+2 S_{c j} S_{j c}+S_{j c}^{2} & <4 S_{c} S_{j} \\
\frac{S_{c j}^{2}+S_{j c}^{2}}{2} & <2 S_{c} S_{j}-S_{c j} S_{j c}
\end{aligned}
$$

Combine above two inequalities:

$$
\frac{S_{c j}^{2}+S_{j c}^{2}}{2}<2 S_{c} S_{j}-S_{c j} S_{j c}<S_{j}\left(S_{c j}-S_{j c}\right)+S_{c j}^{2}
$$

From the derivation of $p_{j}^{*}$, the inequality $S_{c}\left(S_{j c}-S_{c j}\right)+S_{j c}^{2}<2 S_{c} S_{j}-S_{c j} S_{j c}$ implies that $p_{j}^{*}>0$.

To verify this test, we can show that the lefthand side is smaller than $\frac{S_{c j}^{2}+S_{j c}^{2}}{2}$ or that

$$
\begin{aligned}
S_{c}\left(S_{j c}-S_{c j}\right)+S_{j c}^{2} & <\frac{S_{c j}^{2}+S_{j c}^{2}}{2} \\
2 S_{c}\left(S_{j c}-S_{c j}\right)+2 S_{j c}^{2} & <S_{c j}^{2}+S_{j c}^{2} \\
2 S_{c}\left(S_{j c}-S_{c j}\right) & <S_{c j}^{2}-S_{j c}^{2} \\
-2 S_{c}\left(S_{c j}-S_{j c}\right) & <\left(S_{c j}+S_{j c}\right)\left(S_{c j}-S_{j c}\right)
\end{aligned}
$$


Since $p_{c}^{*}<0$ by assumption, Lemma 2 states that $\left(S_{c j}-S_{j c}\right)>0$, showing that the above inequality holds and that only one of the two test conditions can be true.

\section{Firm Competition}

In this section, we consider a duopoly market and show why a firm might voluntarily engage in Bertrand, undifferentiated product, price competition that forces profits to zero in one market segment. The product complement can be used as a credible threat to enter into a market where conditions following entry would argue against a firm's ability to maintain its position.

The first competitive model extends the framework of the previous section to show how a firm prefers to seek market share in one market, while reaping the network externality benefit in the complementary goods market. Any incumbent firm faces the prospect of competition from a firm willing to price at zero or below to gain market share. Microsoft's willingness to price Internet Explorer at zero provides a motivating example. With access to source code from Microsoft's other applications, Internet Explorer displayed significantly greater compatibility with Powerpoint, Word, Excel, and FrontPage than did Netscape. In fact, Internet Explorer could directly display Powerpoint slides without modification complete with animation. It could also directly transfer tables displayed in HTML format to Excel.

\subsection{Complements and Positive Network Externalities}

We again consider two markets for a given information product. The first market has an incumbent monopoly Firm I. We assume that Firm I only participates in market 1. An entrant, Firm E, has the option of entering market 1 with a zero-marginal-cost product. This market is complementary to a second market in which Firm E participates so that $e_{12}>0$. For simplicity, the second market is not complementary to the first - this would only strengthen Firm E's position 
- so the externality is modeled as $e_{21}=0$. In market 1 , we adopt the standard model of linear product differentiation due to Hotelling (1929xxx) as described in Tirole's $1988 \mathrm{xxx}$ text with quadratic costs. In market 2, we introduce a network externality spillover effect from the previous section.

Competition in Market 1 Firm E enters market 1 with a choice of product location. Firms $I$ and $E$ then engage in price competition while Firm $E$ enjoys a monopoly position in market 2. Firm I/s product position is denoted by a and Firm E/s product position is denoted b. Following Tirole (1988), the cost to consumers of purchasing a product rises at the rate $t * x^{2}$ where $x$ measures the gap between the consumer's ideal product and the location of the firm's offering. The cost coefficient $t$ is also assumed to be small enough that the market is fully covered. Otherwise, firms could position themselves far apart to effectively participate in completely separate markets. With respect to their product preferences, consumers are assumed to be uniformly distributed over the interval $[0,1]$ and they share a common willingness to pay for a good that meets their needs. The demand for any good distributed in this region can be found by determining each firm's price and product location dis-utility curve. The indifferent consumer has equal surplus from either firm. Moving in either direction makes one firm's offering preferable to the other firm's customers. This is depicted graphically in Figure 3.

The point at which a consumer is indifferent between the product offered by Firm $I$ and Firm $E$ is denoted by $\mathrm{x}$ in Figure 2. Firm $E$ wins consumers with preferences on the interval $[0, x)$ while Firm I gets consumers with preferences on $(x, 1]$.

Denoting the firm with a superscript, quantities in market 1 are determined by the following set of equations: 


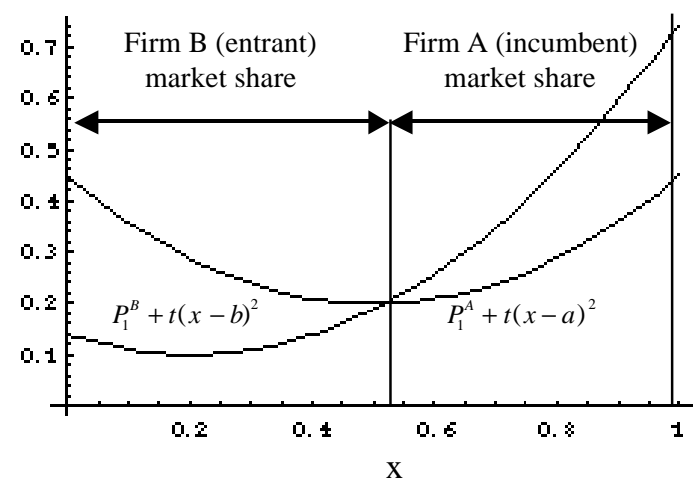

Figure 3: The allocation of market share depends on the choice of location and price. Each firm wins those consumers closest to its product offering up to the point of indifference, $x$.

$$
\begin{aligned}
x & =\frac{p_{1}^{I}-p_{1}^{E}+a^{2} t-b^{2} t}{2 a t-2 b t} \\
q_{1}^{I} & =Q_{1}(1-x) \\
q_{1}^{E} & =Q_{1} x
\end{aligned}
$$

Profits in market 1 are determined by the standard choice of price times quantity:

$$
\begin{aligned}
\pi_{1}^{I} & =p_{1}^{I} Q_{1}(1-x) \\
\pi_{1}^{E} & =p_{1}^{E} Q_{1} x
\end{aligned}
$$

Monopoly in Market 2 We retain the externality effect in market 2 so that quantity is determined by the original equation:

$$
q_{2}^{E}=Q_{2}+e_{12} q_{1}^{E}-\frac{Q_{2}}{V_{2}} p_{2}^{E}
$$

Plugging in $q_{1}^{E}$ from above yields the profit function in market 2: 


$$
\pi_{2}^{E}=p_{2}^{E}\left(Q_{2}+e_{12} x Q_{1}-\frac{Q_{2}}{V_{2}} p_{2}^{E}\right)
$$

Since prices in market 1 are determined endogenously by the level of product differentiation, or choice of location, the entrant anticipates the incumbent's best response and uses this to choose location. The number of consumers in the first market then influence consumption in the entrant's second market. Thus we use the solution concept of a subgame perfect Nash equilibrium to solve for Firm E's location and Firm I's price in market 1 before choosing Firm E's optimal price in market 2.

Given locations, the best response equilibrium prices for market 1 are:

$$
\begin{aligned}
p_{1}^{I *} & =\frac{1}{3}\left(4 a t-a^{2} t-4 b t+b^{2} t\right) \\
p_{1}^{E *} & =\frac{1}{3}\left(2 a t-a^{2} t-2 b t+b^{2} t\right)
\end{aligned}
$$

Combining equations 15 and 17, Firm E's total profit function is:

$$
\pi^{E}=p_{1}^{E} Q_{1} x+p_{2}^{E}\left(Q_{2}+e_{12} x Q_{1}-\frac{Q_{2}}{V_{2}} p_{2}^{E}\right)
$$

Inserting the point of intersection $x$ and the optimal pricing equations 18 and 19 into this profit function allows Firm E to optimize both its choice of location in market 1 and its pricing decision in market 2. Suppressing the algebra, these choices are given by the expressions:

$$
\begin{aligned}
b^{*} & =\frac{e_{12}^{2} Q_{1} V_{2}-(4+a) 8 t Q_{2}+z}{24 t Q_{2}} \\
p_{2}^{E *} & =\frac{V_{2}\left(144 t Q_{2}+e_{12}^{3} Q_{1}^{2} V_{2}+e_{12} Q_{1}\left(16 t Q_{2}(1+a)+z\right)\right)}{288 t Q_{2}^{2}} \\
\text { where } z & =\sqrt{\frac{256(1+a)^{2} t^{2} Q_{2}^{2}+}{32 e_{12} t Q_{2} V_{2}\left((1+a) e_{12} Q_{1}+9 Q_{2}\right)+e_{12}^{4} Q_{1}^{2} V_{2}^{2}}}
\end{aligned}
$$


Proposition 2 A firm may voluntarily enter into Bertrand, or undifferentiated goods, price competition in market 1 if it enjoys a monopoly complement in market 2.

We offer a numerical example to illustrate the subgame perfect Nash equilibrium from Proposition xxx. When Firm I is a monopolist in market 1, it chooses a location at the mid-point of product space to capture maximum market demand with minimum cost, so let Firm I's location be given by $a=\frac{1}{2}$. Then let $t=\frac{1}{4}, e_{12}=1, V_{2}=1, Q_{1}=1, Q_{2}=1$. Plugging these values into the formulae for optimal price and location leads to:

$$
b^{*}=\frac{1}{2}, p_{2}^{E *}=\frac{3}{4}, \pi^{E}=\frac{9}{16}
$$

As a check, we note that the price formulas in market 1 for these parameter values imply $p_{1}^{E}=p_{1}^{I}=\pi^{I}=0$. Moreover, two independent firms pricing the complementary goods, or a myopic integrated firm, would have chosen $b^{*}=0$, leading to combined profits of only .502 versus .563 for optimal choices, a $12 \%$, improvement over the independent choices.

This implies that a firm will willingly forego profits in one market that it can more than recover from a second market. It further implies that Firm E can sustain price competition indefinitely and could, in fact, sustain losses up to the amount of additional profit in market 2. For the incumbent this could lead to market foreclosure. In the absence of its own complementary good, Firm I earns strictly zero profit on sales and it loses its sunk costs.

If Firm I anticipates E's entry, Firm I will not enter the market assuming its product requires an initial investment because these costs are never recovered. Firm I could soften price competition by choosing one end of the product spectrum but this may be insufficient to avoid the effects of a price war. Firm E is seeking market share not profits in Firm I's market. Regardless of the incumbent's choice of location, the entrant can maximize market share by choosing a location $\varepsilon$ to the left or right of Firm I. In fact, the usual solution of escaping competition by choosing $a=1$ or 0 could cede the entire market to the entrant 
who chooses $b=1-\varepsilon$ or $0+\varepsilon$ so that $a=\frac{1}{2}$ is the more conservative solution. Whether this is sufficient reason for $I$ to be in the market then hinges on the relative parameters that govern avoidance, accommodation, and exit.

For information goods, average cost curves are declining due to the high first copy and low additional copy costs. Thus scale is important to remaining profitable. In any case, it should be clear that the existence of a complementary goods market makes $E$ significantly more aggressive.

\subsection{Substitutes and Negative Network Externalities}

In this section, we introduce the idea of strategic substitutes via a negative externality across markets. As a motivating example, we consider the influence that including a Java runtime environment in Netscape had on demand for the Windows operating system. The original intent of Java, as characterized by its developers at Sun Microsystems, was to create a "write once, run anywhere" environment. The proposed mechanism was to include numerous applications programming interfaces (APIs) that would allow programmers direct access to the hardware unmediated by the operating system underneath the browser. Applications could then be written that could run across diverse and independent platforms (US vs. Microsoft - Findings of Fact. Nov. 5 1999). Although the browser and operating system were not direct substitutes - the browser still required an underlying OS - the use of Netscape freed consumers to choose an operating system with less regard for the size of the applications installed base. This might "commoditize" the operating system. The owner of the operating system might then have an incentive to prevent growth in market share of the indirectly competing product.

We can model the negative spillovers using the framework of the previous section. Again, we build on Hotelling's duopoly model of differentiated products in which the choice of product locations determines equilibrium prices. The incumbent in market 1, Firm I, must respond to the choice of product location by the entrant, Firm E, who anticipates this response in determining the best 
location. Exactly as before, optimal prices are given by

$$
\begin{aligned}
p_{1}^{I *} & =\frac{t}{3}(4-a-b)(a-b) \\
p_{1}^{E *} & =\frac{t}{3}(2+a+b)(a-b)
\end{aligned}
$$

Similarly, the point of intersection is $x=\frac{p_{1}^{I}-p_{1}^{E}+t\left(a^{2}-b^{2}\right)}{2 t(a-b)}$ with quantities to each firm given by $q_{1}^{I}=Q_{1}(1-x)$ and $q_{1}^{E}=Q_{1} x$ respectively.

Again, Firm E enjoys a monopoly position in market 2 but this second product is negatively affected by sales of the incumbent's product in market 1 . That is, we can model the influence of sales in market 1 on sales of the competing firm in market 2 as an inter-firm externality. Using superscripts to denote firms, let Firm I's sales in market 1 reduce Firm E's sales in market 2, so that $e_{12}^{I E}<0$. In the last section, we showed that an owned good externality, $e_{12}^{E E}>0$ can be used to motivate free pricing in the competitor's market. To highlight the importance of this new effect, we set owned good externality $e_{12}^{E E}=0$ and show that the same willingness to enter into Bertrand competition holds for a fundamentally different reason, namely, mitigating the loss of sales in a favored market. Retaining the positive sense of the externality, Firm I's sales in market 1 negatively affect Firm E's sales in market 2 yielding the following equation

$$
q_{2}^{E}=Q_{2}-e_{12}^{I E} q_{1}^{I}-\frac{Q_{2}}{V_{2}} p_{2}^{E}
$$

The new total profit equation then becomes

$$
\pi^{E}=p_{1}^{E} Q_{1} x+p_{2}^{E}\left(Q_{2}-e_{12} Q_{1}(1-x)-\frac{Q_{2}}{V_{2}} p_{2}^{E}\right)
$$

Firm $E$ again faces a subgame perfect Nash equilibrium decision. By commiting to a location in market 1, it knows Firm I must respond. It therefore gets to choose $b$ in market 1 knowing that this influences price and 
profits in market 2. Substituting for $x$, the point of intersection, and for optimal market 1 responses $p_{1}^{I *}$ and $p_{1}^{E *}$, Firm $E$ selects $b^{*}$ and $p_{2}^{E *}$. Suppressing the algebra, these are given by

$$
\begin{aligned}
b^{*} & =\frac{e_{12}^{2} Q_{1} V_{2}-(4+a) 8 t Q_{2}+z}{24 t Q_{2}} \\
p_{2}^{E *} & =\frac{V_{2}\left(144 t Q_{2}^{2}+e_{12}^{3} Q_{1}^{2} V_{2}+e_{12} Q_{1}\left(16 t Q_{2}(a-8)+z\right)\right)}{288 t Q_{2}^{2}} \\
\text { where } z & =\sqrt{\begin{array}{c}
256(1+a)^{2} t^{2} Q_{2}^{2}+ \\
32 e_{12} t Q_{2} V_{2}\left((a-8) e_{12} Q_{1}+9 Q_{2}\right)+e_{12}^{4} Q_{1}^{2} V_{2}^{2}
\end{array}}
\end{aligned}
$$

Proposition 3 A firm may voluntarily enter into Bertrand, or undifferentiated goods, price competition in market 1 if it faces a threatened monopoly in market 2.

To illustrate the indirect threat from the cross market externality, let $a=\frac{1}{2}$, $t=\frac{1}{12}, e_{12}=1, V_{2}=1, Q_{1}=1, Q_{2}=1$. Plugging these values into the formulae for optimal price and location then leads to:

$$
b^{*}=\frac{1}{2}, p_{2}^{E *}=\frac{1}{4}, \pi^{E}=\frac{1}{16}
$$

As a check, we note that the price formulas in market 1 for these parameter values imply $p_{1}^{E}=p_{1}^{I}=\pi^{I}=0$.

The illustration in a business setting is straightforward. By including Sun's Java virtual machine in Navigator, Netscape threatened to commoditize operating systems and, even though it was not a direct threat, minimizing Netscape market share became an important goal.

Microsoft would not have given IE away, nor would it have taken on the high cost of enlisting firms in its campaign to maximize IEs usage share and limit Navigators, had it not been focused on protecting the applications barrier [to its operating system]. Judge Thomas Penfield Jackson, Findings of Fact 11-5-99 


\section{Extensions}

\section{Strategic Product Design}

In this section we consider the question of why a firm should spend additional resources to create multiple versions of a product for sale to different markets. Varian (1997) considers the case of versioning information goods by quality and features where firms induce consumers to sort themselves according to their private valuations. We are interested in the case where positive externalities across two markets lead firms to design complementary products. In this case, unbundling can become a dominant strategy.

If we assume a single price across two markets for a bundled information good, then a monopolist chooses price and earns profit as follows:

$$
\begin{aligned}
p_{b}^{*} & =\frac{\left(\left(1+e_{c j}\right) Q_{c}+\left(1+e_{j c}\right) Q_{j}\right) V_{c} V_{j}}{2\left(\left(1+e_{c j}\right) Q_{c} V_{j}+\left(1+e_{j c}\right) Q_{j} V_{c}\right)} \\
\pi_{b}^{*} & =\frac{\left(\left(1+e_{c j}\right) Q_{c}+\left(1+e_{j c}\right) Q_{j}\right)^{2} V_{c} V_{j}}{2\left(e_{c j} e_{j c}-1\right)\left(\left(1+e_{c j}\right) Q_{c} V_{j}+\left(1+e_{j c}\right) Q_{j} V_{c}\right)}
\end{aligned}
$$

We showed above that the optimal unbundled profit when prices are chosen independently for each market is:

$$
\pi_{u}^{*}=\frac{Q_{c} V_{c}+Q_{j} V_{j}+e_{c j} Q_{c} V_{j}+e_{j c} Q_{j} V_{c}}{4-\left(\frac{e_{c j}^{2} Q_{c} V_{j}}{Q_{j} V_{c}}+2 e_{c j} e_{j c}+\frac{e_{j c}^{2} Q_{j} V_{c}}{Q_{c} V_{j}}\right)}
$$

In the context of positive cross-market network externalities, we now show that in the convex regions of interest defined by the Hessian restriction disaggregation dominates.

Proposition 4 When demands across markets exhibit positive cross-externalities, a monopolist can earn strictly greater profit by unbundling a zero-marginal-cost good for sale to each market at independent prices than by selling one product to both markets at a single price.

Proof. To simplify the equations, we focus on the relative market sizes.

Let: 


$$
V_{c}=\delta V, V_{j}=V, Q_{c}=Q, Q_{j}=\varepsilon Q, \delta>0, \varepsilon>0
$$

Then,

$\pi_{u}^{*}-\pi_{b}^{*}=\frac{1}{4} Q V \delta\left(\frac{4 \varepsilon\left(\delta+\varepsilon+e_{c j}+\delta \varepsilon e_{j c}\right)}{4 \delta \varepsilon-\left(e_{c j}+\delta \varepsilon e_{j c}\right)^{2}}-\frac{\left(1+\varepsilon+e_{c j}+\varepsilon e_{j c}\right)^{2}}{\left(1+\delta \varepsilon+e_{c j}+\delta \varepsilon e_{j c}\right)\left(1-e_{c j} e_{j c}\right)}\right)$

All terms are positive by the Hessian condition and the finite market assumption. Cross-multiply to develop the following comparison:

Proof.

$$
\begin{aligned}
& 4 \varepsilon\left(\delta+\varepsilon+e_{c j}+\delta \varepsilon e_{j c}\right)\left(1+\delta \varepsilon+e_{c j}+\delta \varepsilon e_{j c}\right)\left(1-e_{c j} e_{j c}\right)- \\
& \left(1+\varepsilon+e_{c j}+\varepsilon e_{j c}\right)^{2}\left(4 \delta \varepsilon-\left(e_{c j}+\delta \varepsilon e_{j c}\right)^{2}\right)
\end{aligned}
$$

Unbundling dominates when this expression is positive. In fact, this expression simplifies to a perfect square:

$$
\left(2-2 \varepsilon+2 \delta-e_{c j}^{2}+e_{j c}(1+\delta)\left(1+\varepsilon+\varepsilon e_{j c}\right)+e_{c j}\left(e_{j c}(\varepsilon-\delta-1)-1-\varepsilon\right)\right)^{2}
$$

[Authors Note: This proof relies on the restrictive case that consumers in one market place no value on products sold in the other market. This might be true in one direction for products such as Adobe Exchange since a high functionality version of Acrobat Reader is included with the package (along with Distiller which is used to create pdf files), so that consumers would have no need of the free Acrobat Reader product. However, it is probably false in the opposite direction since it is unlikely that all consumers of Acrobat Reader place a zero value on the full featured Adobe Exchange product. We are exploring solutions using a bundling analysis based on Nalebuff (1999) to relax this assumption.] 


\section{Further Applications}

\subsection{Temporal Complements.}

With a shift in interpretation, the framework easily represents temporal complements as well. Under the practice of penetration pricing, a firm introduces a good at a low price in order to generate sales through exposure and word-ofmouth contact. From roughly 1991-1995, the Bare Bones Editor "BBedit" was produced and distributed for free. As it gained in popularity, the copyright owners changed their strategy and offered subsequent products at positive prices. Similarly, in the period after its first formation and before Microsoft entered the market, Netscape Navigator was distributed for free. Netscape, the company, subsequently raised the price until the introduction of Internet Explorer.

\subsection{Upgrades}

The same framework also represents the possible design strategy for upgrades and professional versions. Numerous companies give away an introductory or novice version of their software but charge for the professional version. Ventana Systems allows anyone to download the student edition of their simulation and modeling software for free. The professional version costs $\$ 1200$. Once students have learned the interface and command structure, it is much more attractive to remain within the same product family. This gives users the chance to become used to the good and then to increase their demand for the more advanced features. There are excellent reasons why firms disable functionality in their

products in order to create different versions of their goods. In most of these cases, different versions are created to engage in price discrimination, an effort to cause consumers with intrinsically different demand profiles to self-select on the basis of willingness to pay. A price discrimination model, however, leaves open the question of why any firm should incur development costs on a good for which it anticipates no revenues. 


\subsection{Tangible Goods}

The complementary goods need not, in fact, be wholly information goods. Network exter nalities can arise from goods with tangible and intangible components. The Digita scripting language for digital cameras allows users to create their own extensions to the command sets permissible within the cameras operating system. Kodak has recently held a contest for the best script enhancements and published the results. Giving away this information for free greatly enhances the value of and therefore the demand for the digital cameras offering this capability. Similarly, Intel Corporation freely distributes sophisticated video morphing software. Complex image editing software requires large amounts of memory and processing power. Thus the freely available software increases the demand for their hardware.

\subsection{Temporal Strategic Substitutes}

Introducing new products can also be used to foreclose markets for competitors. As a defensive maneuver, Microsoft could potentially have introduced Internet Explorer as a preemptive strike against a strategic substitute for the Windows operating system. If a non-Microsoft browser became the standard interface to the Internet and launching other applications, it could have diminished the value and hence the profitability of the operating system.

\section{Conclusions}

The model presented here argues for three simple and intuitive results. First, a firm can rationally invest in a product it intends to give away into perpetuity even in the absence of competition. The reason is that increased demand in a complementary fare goods market more than covers the cost of investment in the free goods market. Second, we identified distinct markets for content-providers and end-consumers and showed that either can be a candidate for the free good. The decision on which market to charge rests on the relative elasticities and 
relative network externalities. At sufficient levels, the market with the higher elasticity or greater contribution to demand in the other market is the market to subsidize with the free good. It is also possible to offer fare goods in both markets but to keep one price artificially low.

This contribution is distinct from tying in the sense that consumers need never purchase both goods - unlike razors and blades, the products are standalone goods. It also differs from price discrimination in the sense that the firm may extract no consumer surplus from one of the two market segments, implying that this market would have previously gone un-served.

Third, a firm can use strategic product design to penetrate a market that becomes competitive post-entry. The threat of entry is credible even in cases where it never recovers its sunk costs directly. The model therefore helps to explain several interesting market behaviors such as free goods, temporal complements, tangible complements, and strategic information substitutes. 


\section{Bibliography}

\section{References}

[1] Adams, W.J. and Yellen, J.L. (1976). "Commodity bundling and the burden of monopoly," Quarterly Journal of Economics 90 (August): 475-98.

[2] Bakos, Y. and E. Brynjolfsson (1997). Aggregation and Disaggregation of Information Goods: Implications for Bundling, Site Licensing, and Micropayment Systems. Internet Publishing and Beyond: The Economics of Digital Information and Intellectual Property. D. Hurley, B. Kahin and H. Varian. Cambridge, MA, MIT Press.

[3] Bulow, J. I., J. D. Geanakaplos, et al. (1985). "Multimarket Oligopoly: Strategic Substitutes and Complements." Journal of Political Economy $93(3): 488-511$.

[4] Chuang, J. and M. Sirbu (1997). Bundling \& Unbundling of Information Goods: Economic Incentives for the Network Delivery of Academic Journal Articles. Internet Publishing and Beyond: The Economics of Digital Information and Intellectual Property.

[5] D. Hurley, B. Kahin and H. Varian. Cambridge, MA, MIT Press.

[6] DeGraba, P. (1996). "Why Lever into a Zero Profit Industry: Tying, Foreclosure, and Exclusion." Journal of Economics and Management Strategy $5(3): 433-447$.

[7] Fay, S. and J.K. MacKie-Mason (1999). "Competition Between Firms that Bundle Information Goods." University of Michigan.

[8] Hotelling, H. (1929). "Stability in Competition." Economic Journal 39(3): 433-447.

[9] Katz, M. L. and C. Shapiro (1985). "Network Externalities, Competition, and Compatibility." The American Economic Review 75(3): 424-440.

[10] Lohr, S. (1999). With Acquisition, Sun Takes Aim at Microsoft. New York Times

Nalebuff, B. (1999). "Bundling." Yale School of Management, New Haven, CT.

[11] Shapiro, C. and H. Varian (1999). "The Art of Standards Wars." California Management Review 41(2): 8-32.

[12] Tirole, J. (1988). The Theory of Industrial Organization. Cambridge, Mass., MIT Press. 
[13] Varian, H. (1997). Versioning Information Goods. Berkeley, University of California, Berkeley.

[14] Whinston, M. (1990). "Tying, Foreclosure, and Exclusion." American Economic Review 80(4): 837-859. 